\title{
A new species of Pterinopelma (Araneae: Theraphosidae) from the highlands of the state of Minas Gerais, Brazil and description of the male of P. sazimai
}

\author{
Rogério Bertani ${ }^{*} \&$ Fernando Leal ${ }^{2}$
}

\begin{abstract}
'Laboratório Especial de Ecologia e Evolução, Instituto Butantan. Avenida Vital Brazil 1500, 05503-900 São Paulo, SP, Brazil.

'Laboratório de Herpetologia, Departamento de Zoologia, Instituto de Ciências Biológicas, Universidade Federal de Minas Gerais. Avenida Antônio Carlos 6627, Pampulha, 31270-901 Belo Horizonte, MG, Brazil.

E-mail: fernando.lealbh@gmail.com

‘Corresponding author.E-mail: rogerio.bertani@butantan.gov.br, rogerio.bertani@uol.com.br
\end{abstract}

\begin{abstract}
We describe a new species of tarantula from the highlands of the state of Minas Gerais, Brazil. Males of the new species can be distinguished from congeners by having palpal bulb keels weakly developed, and metatarsus I strongly curved, touching apex of retrolateral spur when folded. Females can be distinguished by the color pattern, carapace and legs black with conspicuous white rings on distal femora, patellae, tibiae, and metatarsi. The male of Pterinopelma felipeleitei sp. nov. was previously misidentified and described under the name Pterinopelma sazimai Bertani, Nagahama \& Fukushima, 2011. The true male of $P$. sazimai is herein described from a specimen collected near the type locality. Similar to the conspecific female, this male has characteristic blue iridescent setae covering the carapace, chelicerae, legs, and palps. The new species is sympatric with P. sazimai. Both species inhabit a habitat locally known as 'campos rupestres'.
\end{abstract}

KEY WORDS. Espinhaço Mountain Range, tarantula, taxonomy.

Pterinopelma Pocock, 1901 comprises two valid species of tarantulas, P. sazimai Bertani, Nagahama \& Fukushima, 2011, and the type species $P$. vitiosum (Keyserling, 1891). Individuals of these species inhabit hilly environments in Brazil. Pterinopelma vitiosum is found in the state of Rio Grande do Sul, whereas $P$. sazimai is distributed in the states of Minas Gerais and Bahia (Bertani et al. 2011). Pterinopelma is related to Lasiodora C.L. Koch, 1850, Nhandu Lucas, 1983 and Vitalius Lucas, Silva \& Bertani, 1993. The presence of denticles on the prolateral inferior male palpal bulb keel has been proposed as a generic synapomorphy of Pterinopelma (Bertani et al. 2011).

During a herpetological survey in the highlands of the Espinhaço Mountain Range in Minas Gerais, the second author (FL) found a peculiar female and an immature male of a theraphosid species. They were very similar in general appearance and color pattern: very dark with conspicuous white rings and stripes over the legs and palps. In the laboratory, after several weeks, the male molted and reached maturity, and the specimens were sent to the first author (RB) for identification. The male was identified as $P$. sazimai; the female, however, did not correspond to the female of that particular species, since it lacks the iridescent, metallic blue coloration that characterizes it (BERTANi et al. 2011). Concomitantly, a mature theraphosid male specimen was collected by colleagues at the type locality of $P$. sazimai. This male has the characteristic coloration of the $P$. sazimai female. Thus, it became clear that there are two sympatric theraphosine species of similar size in the highlands of the Espinhaço Mountain range, one of which was undescribed. This new species, belonging to Pterinopelma, is herein described, and the true male of $P$. sazimai is described for the first time.

\section{MATERIAL AND METHODS}

The general format of the description follows BERTANI (2001) and RAVEN (2005), with some modifications. The terminology used for the male palpal bulb follows BERTANI (2000), for urticating setae follows CoOKE et al. (1972) and BERTANI \& GUADANUCCI (2013), and for leg spines follows PetrunKevitch (1925) with modifications proposed by BERTANI (2001). All measurements are in millimeters. Measurements of the legs and palp were taken from the dorsal aspect of the left side (unless appendages were lost or obviously regenerated) with a Mitutoyo ${ }^{\circledR}$ digital caliper, 
which had an error of $0.005 \mathrm{~mm}$, rounded up to two significant decimals. Structures of the left side of the specimens were chosen for descriptions. A Leica LAS Montage and LAS 3D module mounted on a Leica M205C dissecting microscope were used for image capture and measurements of other spider structures. Abbreviation: (A) apical keel, (ALE) anterior lateral eye, (AME) anterior median eye, (ap) apical, (ITC) inferior tarsal claw, (MM) dorsal median region of abdomen, (MP) dorsal median posterior region of abdomen, (PI) prolateral inferior keel, (PLE) posterior lateral eye, (PME) posterior median eye, (PMS) posterior median spinneret, (p) prolateral, (PS) prolateral superior keel, (r) retrolateral, (R) retrolateral keel, (SA) subapical keel, (STC) superior tarsal claws, (v) ventral.

Specimens of the following institutions were examined: IBSP - Instituto Butantan, São Paulo; MNRJ - Museu Nacional, Rio de Janeiro; ZUEC - Museu de Zoologia da Universidade Estadual de Campinas, Campinas.

Geographical coordinates: primary sources are between round brackets, secondary sources (Google Earth ${ }^{\odot}$ ) between square brackets. The coordinates from the secondary source were obtained from the center of the municipality cited in the specimen label and are in DMS (Degrees, Minutes and Seconds) format rounded off to minutes.

\section{TAXONOMY}

\section{Theraphosidae Thorell,1869 Pterinopelma Pocock, 1901}

Pterinopelma Pocock, 1901: 551 (type species by monotypy Eurypelma vitiosa Keyserling, 1891; Holotype male, Brazil, Taquara, in BMNH, examined); Mello-Leitão, 1923: 183, 1943: 153; Petrunkevitch 1928: 80; 1939a: 261; 1939b: 567; Bonnet 1958: 3827; Gerschman \& Schiapelli 1978: 86; Valerio 1980: 276; Bertani, Nagahama \& Fukushima 2011: 3.

Diagnosis (emended from BerTaNi et al. 2011). Pterinopelma resembles Lasiodora, Vitalius and Nhandu in lacking accessory prolateral keels and having prolateral superior, prolateral inferior, retrolateral, subapical and apical palpal keels in male; and by the short spermathecae, separated by a heavily sclerotized short area in female. Both sexes can be distinguished from Lasiodora by the absence of stridulatory setae on the prolateral coxae. From Nhand $u$ and Vitalius, Pterinopelma males are distinguished by the presence of denticles in the prolateral inferior keel (P. vitiosum) and the weakly developed male palpal bulb keels ( $P$. felipeleitei sp. nov.). Females of Pterinopelma can be distinguished from Nhandu females by the absence of long setae on the carapace and from Vitalius females by having the sternum as wide as long, or wider than long.

Species included. Pterinopelma vitiosum Pocock, 1901 and Pterinopelma felipeleitei sp. nov.

Remarks. The examination of morphological structures of the true male of $P$. sazimai suggests that the species does not belong to Pterinopelma. However, we refrain from making taxonomic changes until a cladistic analysis including this species is carried out and its position is elucidated. See the discussion for additional information.

\section{Pterinopelma sazimai Bertani, Nagahama \& Fukushima, 2011 \\ Figs. 1-7, 15}

Pterinopelma sazimai Bertani, Nagahama \& Fukushima, 2011: 8, f. 7-16 (in part, only the female); World Spider Catalog, 2015.

Diagnosis. Males of Pterinopelma sazimai can be distinguished from all congeners by having in conjunction: the palpal bulb with well-developed PS, PI, R, A, and SA keels (Figs. 6-7); embolus slender at its distal portion (Figs. 6-7); absence of stridulatory setae on prolateral face of coxa I; bifid tibial spur with almost straight retrolateral branch (Fig. 5); and metatarsus I, when folded, touching the apex of retrolateral tibial spur. Females of this species can be distinguished by having the following combination of traits: short spermathecae, separated by a short, heavily sclerotized area; absence of stridulatory setae on prolateral face of coxa I; absence of long setae on the carapace; presence of urticating setae of type III on abdomen dorsum; and a sternum that is longer than wide. Additionally, both males and females have carapace, chelicerae, and legs covered with blue iridescent setae (Figs. 1, 19).

Description. Male (MNRJ 5060) (Figs. 1-7, 19). Carapace 14.56 long, 13.08 wide, chelicerae 7.89. Legs (femur, patella, tibia, metatarsus, tarsus, total): I: $14.17,7.84,12.25,11.9,7.15$, 53.31. II: 13.07, 7.05, 11.12, 11.61, 6.87, 49.72. III: 11.73, 5.94, 9.9, 12.52, 6.6, 46.69. IV: 14.0, 6.43, 12.61, 17.74, 7.54, 58.32. Palp: $8.83,5.21,8.11,-, 2.85,25.0$. Midwidths: femora I-IV = 2.33, 2.54, 3.03, 2.72, palp $=1.97$; patellae I-IV $=2.47,2.51$, $2.36,2.59$, palp $=2.11$; tibiae I-IV $=2.01,1.74,1.86,1.73$, palp $=2.14$; metatarsi I-IV $=1.12,1.14,1.12,1.21$; tarsi I-IV $=0.97$, 0.92, 0.86, 0.76, palp $=1.89$. Abdomen 13.45 long, 8.34 wide . Spinnerets: PMS, 1.62 long, 0.56 wide, 0.63 apart; PLS, 2.61 basal, 1.76 middle, 2.64 distal; midwidths $0.9,0.76,0.55$, respectively. Carapace. Length to width 1.11 ; cephalic area moderately raised, thoracic striae deep. Fovea: deep, straight, 2.56 wide. Carapace covered with short, slender, dense setae, bordered with long setae pointing out (Fig. 1). Eyes and eye tubercle. Tubercle 0.77 high, 1.46 long, 2.15 wide. Clypeus 0.15 wide. Anterior row procurved, posterior recurved. Sizes and inter-distances: AME 0.40, ALE 0.55, PME 0.34, PLE 0.53, AME-AME 0.32, AME-ALE 0.15, AME-PME 0.13, ALE-ALE 1.16, ALE-PME 0.32, PME-PME 0.84, PME-PLE 0.12, PLE-PLE 1.34, ALE-PLE 0.26, AME-PLE 0.4. Eye group 2.12 wide, 1.07 long. Maxillae. Length 4.14, width 2.59. Cuspules: ca. 328 spread over ventral inner heel. Lyra absent (Fig. 2). Labium: 1.7 long, 2.62 wide, with ca. 191 cuspules spaced by less than one diameter from each other on the anterior third center (Fig. 2). Labio-sternal groove shallow, flat, with two large sigilla. Chelicerae. Rastellum absent, basal 


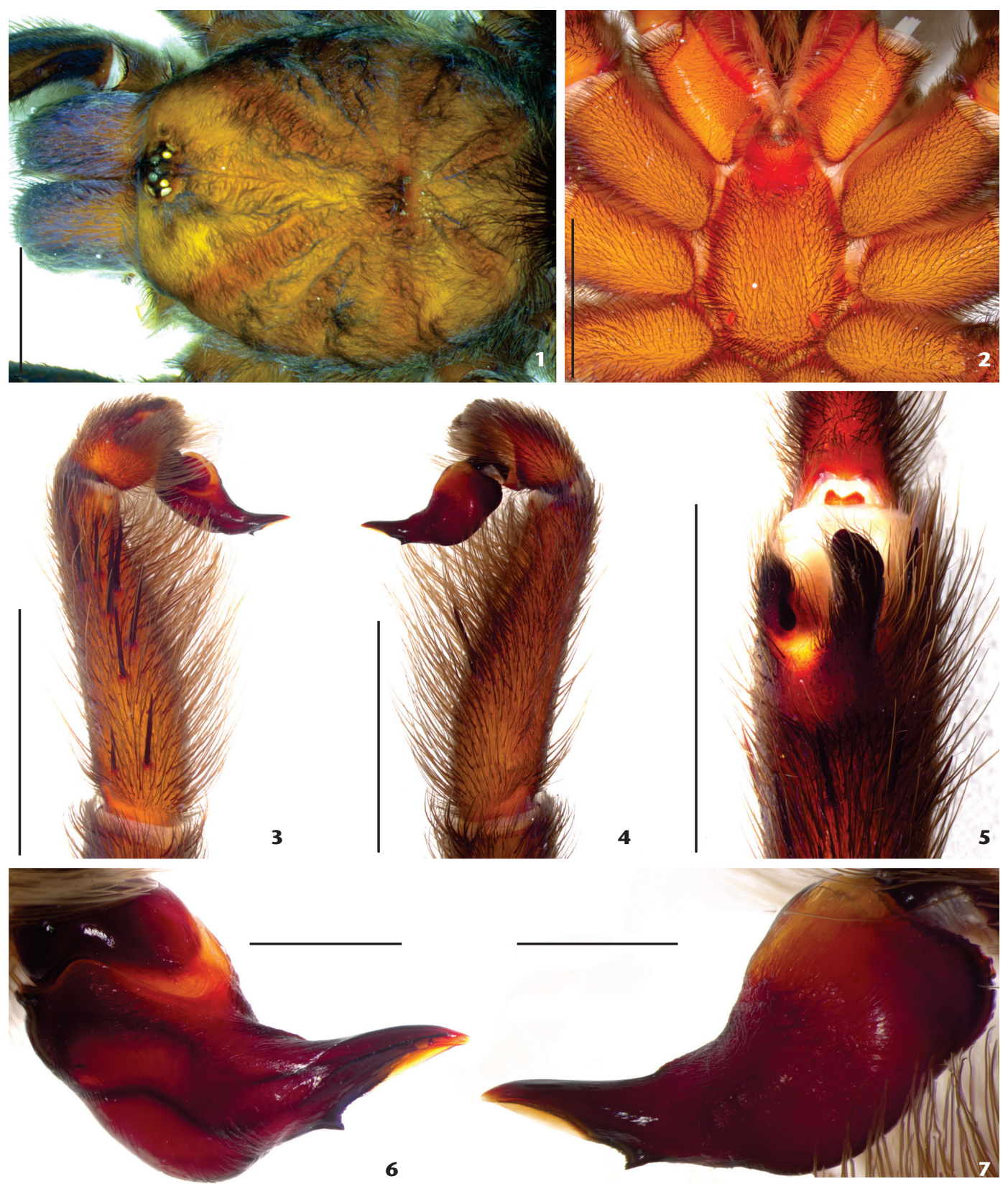

Figures 1-7. Pterinopelma sazimai, male, MNRJ 5060: (1) carapace and chelicerae; (2) sternum, maxillae, labium and coxae; (3-4) left palp, (3) prolateral, (4) retrolateral; (5) left leg I tibial spur, ventral; (6-7) left male palpal bulb, (6) prolateral, (7) retrolateral. Scale bars: $1-5=5 \mathrm{~mm}, 6-7=1 \mathrm{~mm}$.

segment with 10 teeth on promargin and small teeth on basal area. Sternum. Length 6.89, width 5.28. Posterior angle rounded, not separating coxae IV. Sigilla: first pair not evident; second small, rounded; third ovals; second and third less than one diameter from margin (Fig. 2). Legs: leg formulla: IV I II III. Clavate trichobothria: on distal $2 / 3$ of tarsi I-IV. Leg coxae: with sparce soft setae; stridulatory or modified setae lacking. Scopula. Retrolateral femur IV scopulate. Tarsi I-III fully scopulate; IV divided by a row of sparse setae. Metatarsi I fully scopulated; II $3 / 5$, III $1 / 3$, IV $1 / 6$ distal scopulate. Metatarsus IV not divided by row of setae. Spination: palp: femur p0-0-1, patella p1, tibia v2-5-1; leg I: femur p0-0-1, patella p1, tibia v3-2-4, p1-1-0, r1-0-1, 
metatarsus v1-0-3ap, p1-0-1; leg II: femur p0-0-2, patella p1, tibia v2-3-5(3ap), p1-1-0, r0-1-1ap; metatarsus v2-0-3ap, p1-0-1ap, r0-1-1; leg III: femur p0-0-1, r0-1-1, patella r1, tibia v5-4-5(3ap), p1-1-1, r1-1-1, metatarsus v4-3-5(3ap), p1-1-1ap, r0-1-1; leg IV: femur p0-0-1, r0-0-1, patella v1, tibia v4-5-5(3ap), p1-1-1, r0-21, metatarsus, v22(3ap), p0-1-0, r0-1-1. Claws: ITC absent from all legs; STC with a single row of ca. 6 small teeth. Urticating setae. Type I with region " $\mathrm{A}$ " longer or equal to region " $\mathrm{B}$ ", 0.28 to 0.37 long, on MM area; Type III 0.66 long, on MM and MP areas. Distribution of urticating setae on abdomen corresponds to fig. 7 in Bertani \& Guadanucci (2013). Palp (Figs. 3-4, 6-7). Palpal bulb pyriform; embolus short, slightly flattened laterally at distal region, apex long and slender. Prolateral keels present. PS forming embolus edge distally. A present, medially developed. $\mathrm{R}$ present, sharp. SA present, well developed. Bifid tibial spur with branches originating from common base, both almost straight, retrolateral longer (Fig. 5). Metatarsus I slightly curved, when folded touches apex of retrolateral tibial spur. Color pattern. Carapace, chelicerae and legs dark brown, covered with blue iridescent setae (Fig. 19). Coxae of legs and sternum dark brown, covered with grayish setae (Fig. 2). Labium and maxillae reddish brown. Abdomen dorsally light brown on anterior half, area with urticating setae on posterior half black; all abdomen dorsally with abundant long reddish setae. Abdomen ventrally brown. Femora, patellae, tibiae and metatarsi of legs and palp lacking light stripes and white rings on apex of articles.

Type material. Female Holotype: BraziL, Bahia: Andaraí (Parque Nacional da Chapada Diamantina, $12^{\circ} 46^{\prime} 9.21^{\prime \prime} \mathrm{S}$, $41^{\circ} 28^{\prime} 6.79^{\prime \prime} \mathrm{W}, 1262 \mathrm{~m}$ a.s.l.), 17 February 2008, C.S. Fukushima, R. Bertani \& R.H. Nagahama, ZUEC, examined.

Paratype female: BraziL, Minas Gerais: Santana do Riacho (Parque Nacional da Serra do Cipó, [S19 ${ }^{\circ} 17^{\prime}$ W43 $\left.35^{\prime}\right]$ ), 13-15 December 1971, I. Sazima et al., ZUEC, examined.

Additional material. BraziL, Bahia: Andaraí (Chapada Diamantina, Igatu [12 $53^{\prime}$ S, $\left.\left.41^{\circ} 19^{\prime} \mathrm{W}\right]\right)$, male, 10 March 2012, A.P.L. Giupponi, G.S. Miranda, M.E. Bichuette \& J.E. Gallão (MNRJ 5060).

Distribution. Highlands (up $1100 \mathrm{~m}$ a.s.l.) of the Espinhaço Mountain range, states of Minas Gerais and Bahia, Brazil (BERTANi et al. 2011).

\section{Pterinopelma felipeleitei sp. nov.}

\section{Figs. 8-18, 20}

urn:Isid:zoobank.org:act:66866038-7BB2-4F73-8233-E8C3A697E781

Pterinopelma sazimai Bertani, Nagahama \& Fukushima, 2011: 8,

f. 7-16 (in part: only the male); World Spider Catalog, 2015.

Diagnosis. Males of $P$. felipeleitei sp. nov. can be distinguished from congeners by the following combination of characters: weakly developed palpal bulb keels (Figs. 13-18); and strongly curved metatarsus I (Fig. 12) touching apex of retrolateral spur when folded. Females can be distinguished by having : short spermathecae separated by short, heavily sclerotized area (Fig. 10); absence of stridulatory setae on prolateral face of coxa I; absence of long setae on the carapace (Fig. 8); absence of urticating setae of type III on abdomen dorsum; sternum as long as wide (Fig. 9); and carapace and legs black with conspicuous white rings on distal femora, patellae, tibiae, and metatarsi (Fig. 20).

Description. Female holotype (MNRJ 6873) (Figs. 8-10, 20). Carapace 19.88 long, 18.32 wide, chelicerae 9.94. Legs (femur, patella, tibia, metatarsus, tarsus, total): I: 15.69, 9.45, 10.27, 9.82, 6.21, 51.44. II: $14.22,8.46,9.33,9.44,5.69,47.14$. III: 13.15 , 7.46, 9.01, 10.70, 5.56, 45.88. IV: 15.38, 8.37, 11.83, 15.48, 5.54, 56.6. Palp: 11.43, 7.98, 7.71, -, 7.28, 34.4. Midwidths: femora $\mathrm{I}-\mathrm{IV}=3.83,3.96,4.41,3.87$, palp $=2.87$; patellae $\mathrm{I}-\mathrm{IV}=3.99,3.7$, $3.72,3.69$, palp $=3.31$; tibiae I-IV $=3.58,3.13,3.23$, 3.01, palp = 3.05; metatarsi I-IV $=2.37,2.15,2.37,2.12$; tarsi I-IV $=2.22$, $2.17,2.15,2.19$, palp = 2.54. Abdomen 20.18 long, 15.56 wide. Spinnerets: PMS, 2.64 long, 1.09 wide, 1.72 apart; PLS, 2.93 basal, 2.35 middle, 3.01 distal; midwidths $1.92,1.87,1.36$, respectively. Carapace. Length to width 1.08; cephalic area noticeably raised, thoracic striae deep. Fovea: deep, straight, 4.10 wide. Carapace covered with short, slender, dense setae and several sparse longer setae, bordered with long setae pointing out (Fig. 8). Eyes and eye tubercle. Tubercle 1.02 high, 2.21 long, 2.81 wide. Clypeus 0.1 wide. Anterior row procurved, posterior recurved. Sizes and inter-distances: AME 0.51, ALE 0.58, PME 0.32, PLE 0.60, AMEAME 0.53, AME-ALE 0.33, AME-PME 0.35, ALE-ALE 2.02, ALE-PME 0.62, PME-PME 1.36, PME-PLE 0.14, PLE-PLE 2.06, ALE-PLE 0.45, AME-PLE 0.68. Eye group 2.72 wide, 1.49 long. Maxillae. Length 6.95, width 4.67. Cuspules: ca. 268 spread over ventral inner heel. Lyra absent (Fig. 9). Labium 2.32 long, 2.96 wide, with ca. 100 cuspules spaced by less than one diameter from each other on the anterior third center. Labio-sternal groove shallow, flat, without evident sigilla. Chelicerae. Rastellum absent, basal segments with 12 teeth on promargin; and small teeth on basal area. Sternum. Length 9.15, width 8.86. Posterior angle rounded, not separating coxae IV. Sigilla: three pairs, all small, rounded, one diameter from margin. Legs: formulla: IV I II III. Clavate trichobothria: on distal 2/3 of tarsi I-IV. Leg coxae: with sparce soft setae; stridulatory or modified setae lacking. Scopula. Retrolatral femur IV scopulate. Tarsi I-IV fully scopulate. Metatarsi I-II fully scopulated; III 1/2, IV 1/4 distal scopulate. Metatarsus IV not divided by row of setae. Spination: palp: femur p0-0-1ap, patella 0, tibia v0-0-4ap, p2-2-1ap; leg I: femur p0-0-1, patella 0, tibia v0-1-3ap, metatarsus v0-0-1ap; leg II: femur p0-0-2, patella 0, tibia v0-1-2ap, p1-1-0; metatarsus v1-0-2ap; leg III: femur p0-0-1, patella p1, tibia v0-23ap, p1-1-1, r1-1-1, metatarsus v2-2-2ap, p1-1-2(1ap), r0-1-1ap; leg IV: femur p0-0-1, r0-0-1, patella 0, tibia v1-3-3(2ap), p1-1-1, r1-1-0, metatarsus v18(2ap), p1-1-1, r0-1-1ap. Claws: ITC absent from all legs; STC with a single row of 6-7 small teeth. Urticating setae. Type I with region "A" longer than region "B", 0.25 to 0.28 long, on anterior and lateral areas of abdomen dorsum; Type III apparently lacking, but median and posterior abdominal areas are bald (see remarks). Genitalia. Two short spermathecae separated by heavily sclerotized short area, spermathecal stalk narrower than spermathecal bulb (Fig. 10). Color pattern (Fig. 20). Carapace black 

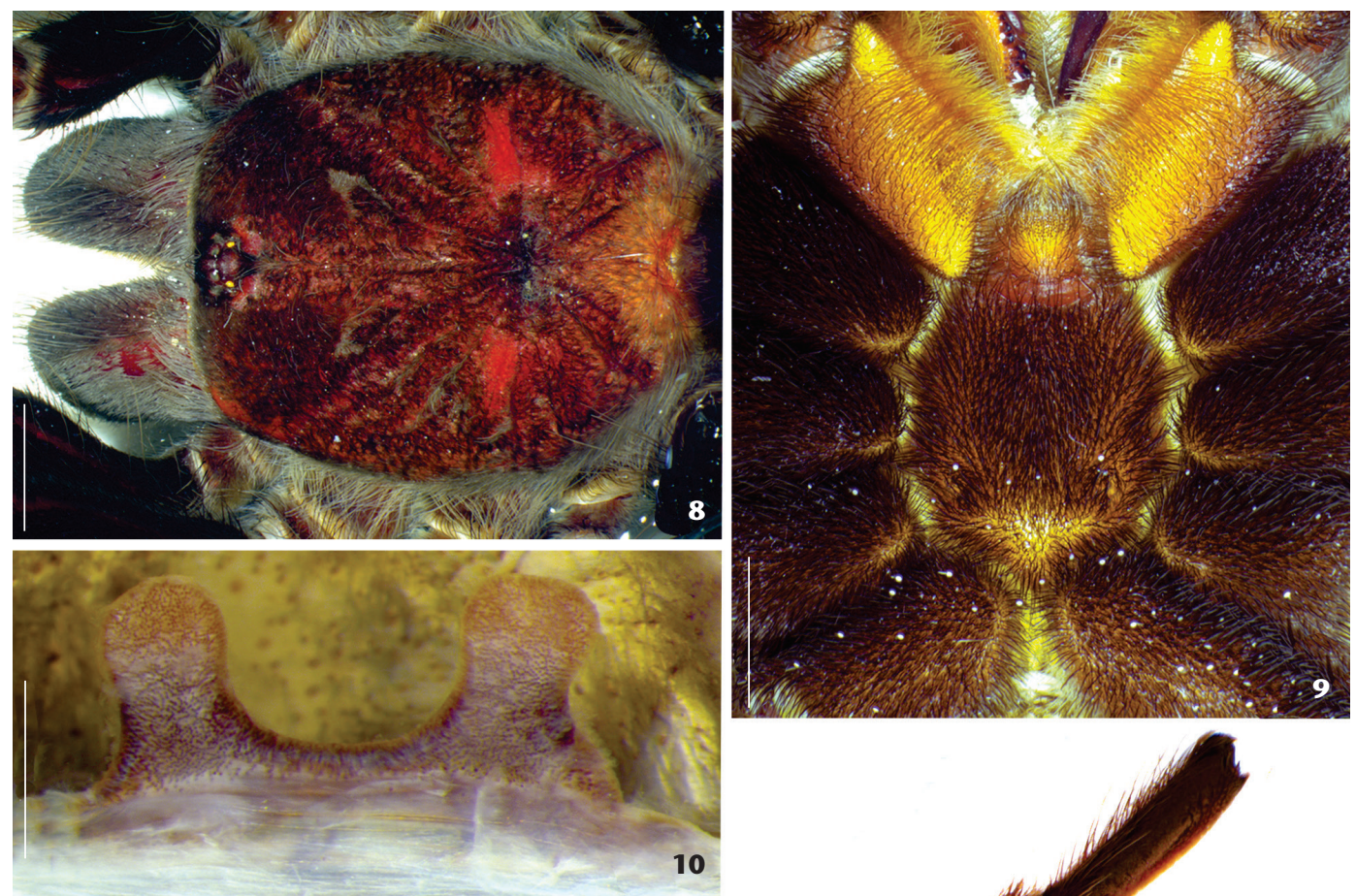

10

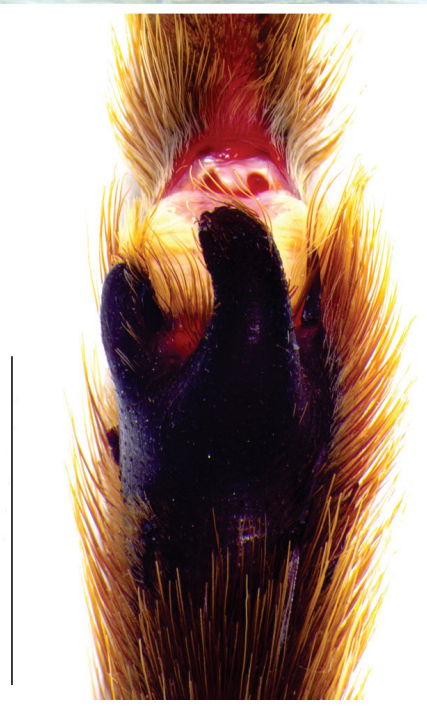

11

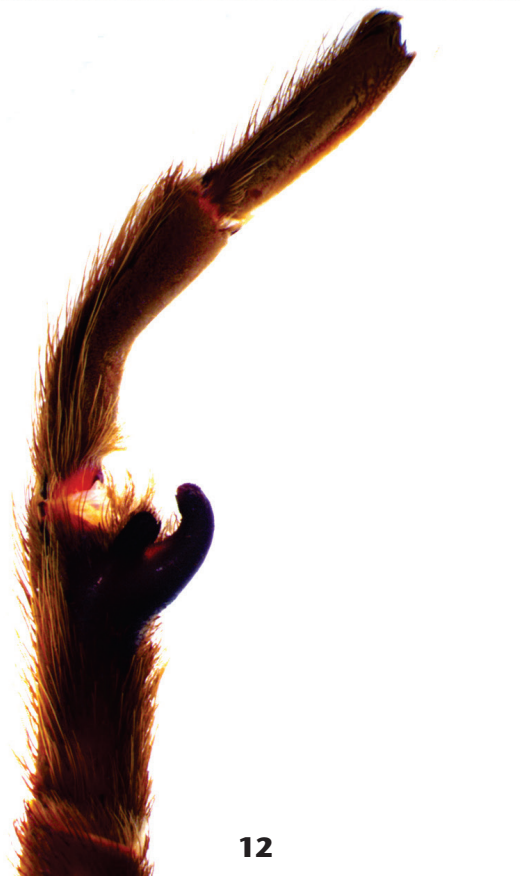

Figures 8-12. Pterinopelma felipeleitei sp. nov. (8-10) Holotype female, MNRJ 6873: (8) carapace and chelicerae; (9) sternum, maxillae, labium and coxae; (10) spermathecae; (11-12) male, IBSP 111631: (11) left leg I tibial spur, ventral; (12) left leg I, prolateral. Scale bars: $8-9,11-12=5 \mathrm{~mm}, 10=1 \mathrm{~mm}$.

with several whitish setae, bordered by whitish setae. Chelicerae, sternum, coxae black (Fig. 9). Labium, maxillae reddish brown (Fig. 9). Legs and palp black with broad, conspicuous white rings on distal femora, patellae, tibiae and metatarsi. All legs and palp with two conspicuous white stripes on dorsum of femora, patellae and tibiae, a single short conspicuous white stripe on basal metatarsi. Abdomen black with long brown setae on dorsum (Fig. 20).
Male: described by BERTANI et al. 2011, as the male of $P$. sazimai.

Type material. Female Holotype: BraziL, Minas Gerais: Serro (Parque Estadual Pico do Itambé, Serra do Arrependido Condado, $18^{\circ} 27^{\prime} 38^{\prime \prime} \mathrm{S}, 4^{\circ} 22^{\prime} 11^{\prime \prime} \mathrm{W}, 1421 \mathrm{~m}$ a.s.l.), 23 November 2012, F. Leal (MNRJ 6873). Paratypes: BrazIL, Minas Gerais: Santana do

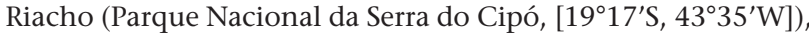



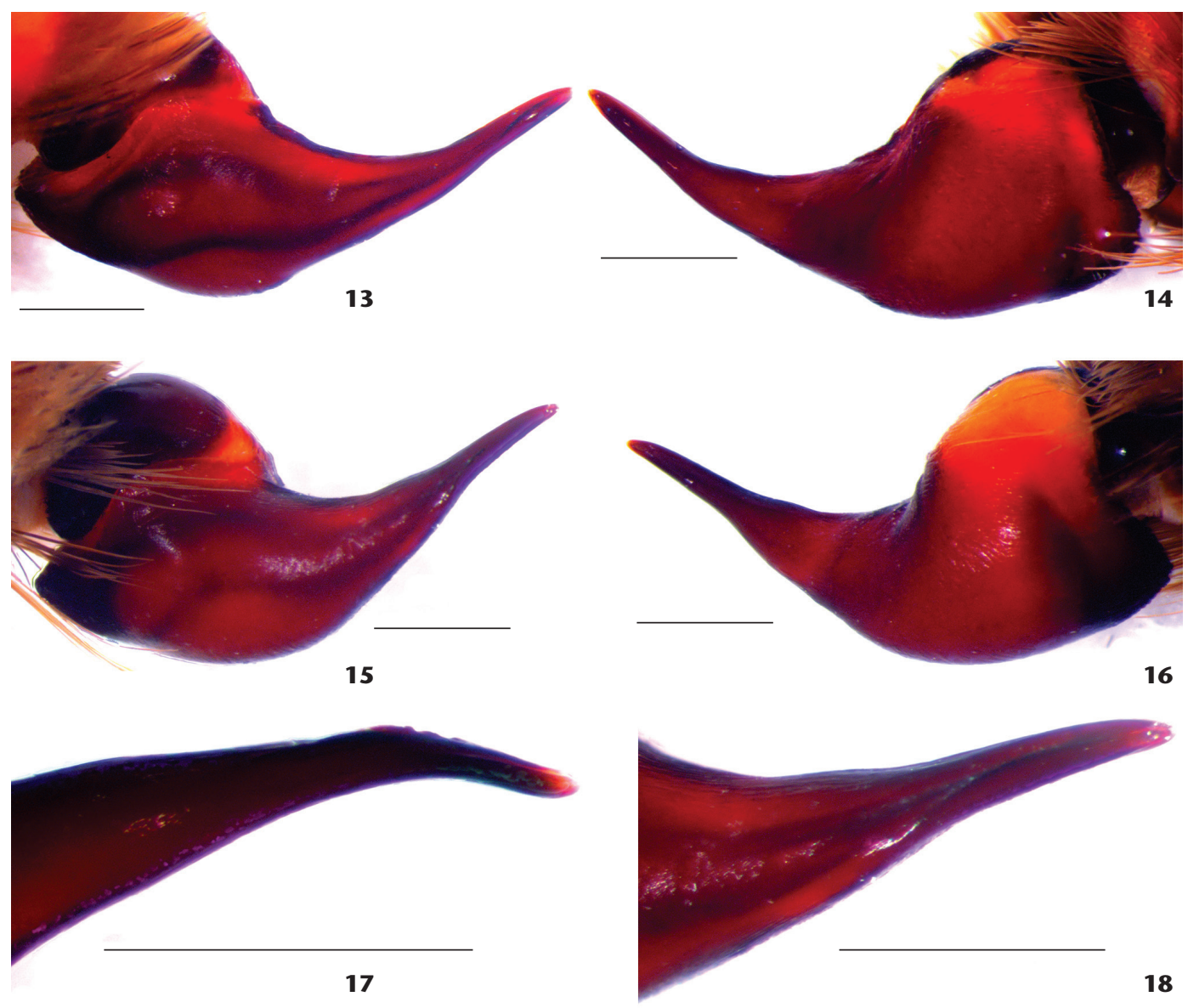

Figures 13-18. Pterinopelma felipeleitei sp. nov., left male palpal bulb. (13-14) IBSP 111631: (13) prolateral; (14) retrolateral; (15-16) MNRJ 6875: (15) prolateral; (16) retrolateral; (17) IBSP 111631:, embolus, prolateral; (18) MNRJ 6875: embolus, prolateral. Scale bars: 1 mm.

two males, May 1993, M.T.V.A. Campos (IBSP 111631); Morro do Pilar (Parque Nacional da Serra do Cipó, Alto Palácio, $19^{\circ} 17^{\prime} 51.39^{\prime \prime} \mathrm{S}, 43^{\circ} 30^{\prime} 34.47^{\prime \prime} \mathrm{W}$; $1372 \mathrm{~m}$ a.s.l.), one female, 12 April 2014, F. Leal (MNRJ 6874); Serro (Parque Estadual Pico do Itambé, Serra do Arrependido Condado, 18²7'38”S, $43^{\circ}$ 22'11"W; $1421 \mathrm{~m}$ a.s.l.), one male, 23 November 2012, F. Leal (MNRJ 6875) matured in captivity.

Distribution. Pterinopelma felipeleitei sp. nov. is known from Serra do Arrependido Condado (Parque Estadual Pico do Itambé, municipality of Serro) (Fig. 23) and PARNA Serra do Cipó, which includes the municipalities of Morro do Pilar (Fig. 24) and Santana do Riacho. The three sites where individuals of the species were found belong to the Espinhaço Mountain Range and are located in the central portion of the state of Minas Gerais in Brazil.

Etymology. The specific name is a tribute to the herpetologist Felipe S. F. Leite (Universidade Federal de Viçosa-Campus Florestal) for his extensive contribution to the knowledge of the biodiversity of the Espinhaço Mountain Range.
Remarks. The female paratype (MNRJ 6874) has dorsal abdominal setae covering intact and only type I urticating seta was found. Therefore, we consider that type III urticating seta is absent in this species. The distribution of urticating setae on abdomen corresponds to fig. 5 in BerTANi \& GuADANUCCI (2013). BERTANi et al. (2011) considered the presence of denticles on the prolateral inferior male palpal bulb keel (Fig. 17) a putative synapomorphy of Pterinopelma. However, these denticles were not noted in the recently collected male (MNRJ 6873) (Fig. 18). The keels of the male palpal bulb are strongly reduced in this species (Figs. 13-18) and it is difficult to examine them in detail. The absence of these keels in the specimen can be due to morphological variation, but can also indicate that the specimen analyzed in BERTANI et al. (2011) is damaged or even anomalous. Therefore, Pterinopelma is defined by a particular combination of characters listed above in the generic diagnosis.

Natural History. Pterinopelma felipeleitei occurs in the highlands (above $1100 \mathrm{~m}$ a.s.l.) and in open rock fields called "Campos Rupestres," a typical phytophysiognomy of the Espin- 

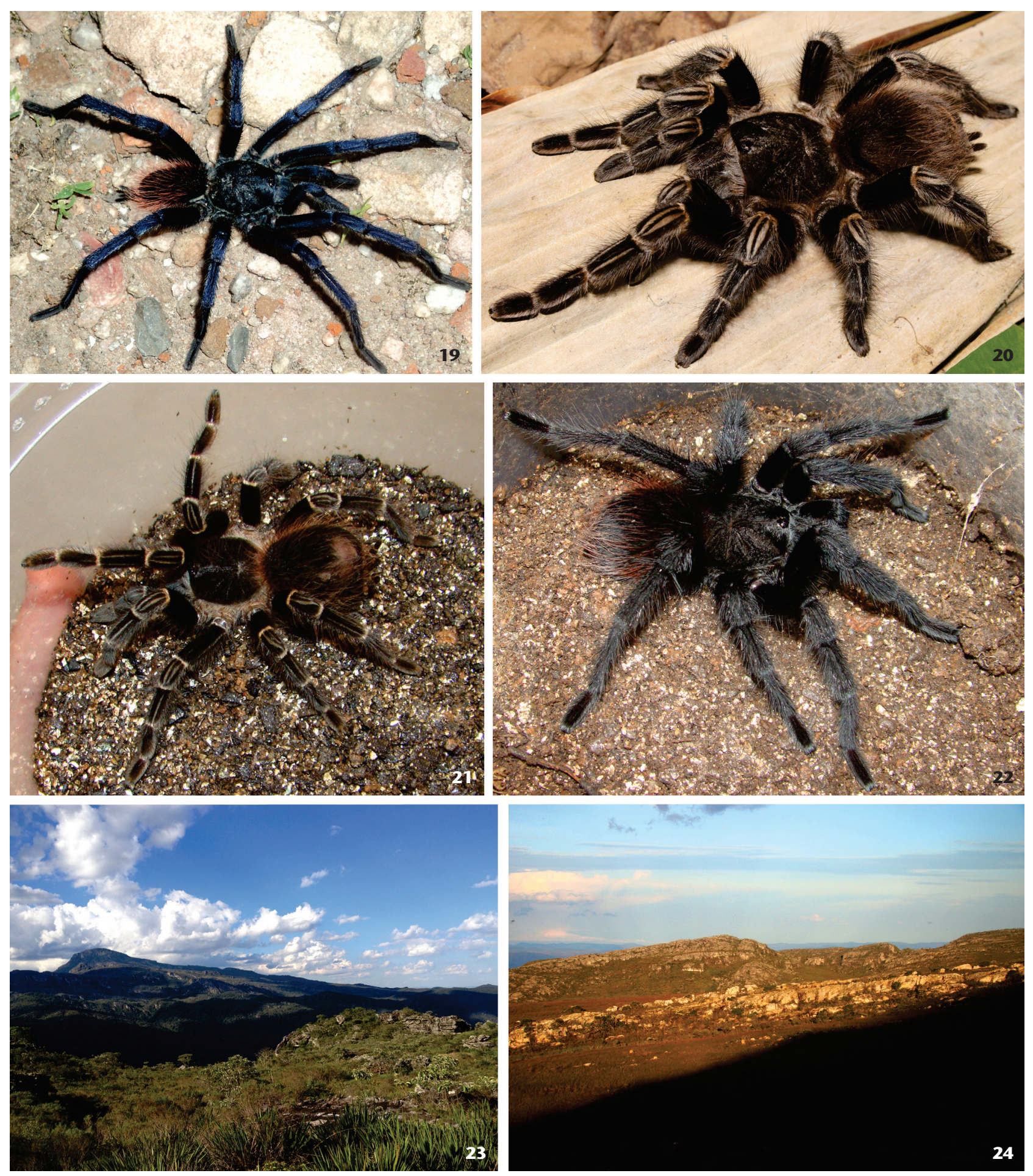

Figures 19-24. (19-22) Habitus: (19) Pterinopelma sazimai living male, MNRJ 5060; (20) Pterinopelma felipeleitei sp. nov. living female, holotype MNRJ 6873; (21-22) male, MNRJ 6875: (21) immature; (22) after reaching maturity; (23-24) habitat: (23) Parque Estadual Pico do Itambé, municipality of Serro, state of Minas Gerais, Brazil, (24) Parque Nacional da Serra do Cipó, municipality of Morro do Pilar, state of Minas Gerais, Brazil. Photos: (19) Alessandro Giupponi, (20) Rogério Bertani, (21-24) Fernando Leal. 
haço Mountain Range (Figs. 23-24). The new species is associated with mountain tops formed mainly by rocky outcrops, sandy soil, and herbaceous vegetation. This type of environment is predominantly arid in the dry season and is marked by the formation of temporary streams in the rainy season. The female holotype and the paratype (MNRJ 6875) from Serro were collected at night on rocks, while the paratype (MNRJ 6874) from Morro do Pilar was found in the source of a temporary stream, on a bromeliad, preying on a cricket.

\section{DISCUSSION}

Bertani et al. (2011) revalidated Pterinopelma after examining the holotype of the type species ( $P$. vitiosum) and comparing it with freshly collected specimens, including the unknown female. In the same paper, a second species, $P$. sazimai, was described from the Espinhaço Mountain range of the states of Bahia (Chapada Diamantina, holotype female) and Minas Gerais (Serra do Cipó, juvenile paratype female and two paratype males), Brazil. The holotype female of $P$. sazimai has conspicuous blue iridescent setae covering its body, and the described paratype male is completely black. The paratype males were collected from the same place in Serra do Cipó National Park, where juvenile and female specimens of $P$. sazimai were also collected (BERTANi et al. 2011). This made them suspect that they were conspecifics. However, additional theraphosine specimens from Chapada Diamantina and Serra do Cipó (and other highlands in Minas Gerais) showed that two related species with individuals of similar size inhabit in the same environment of the Campos Rupestres of the Espinhaço Mountain range.

One of these specimens, a male, has the blue iridescent setae covering its body (Fig. 19) and was found near the type locality of $P$. sazimai. This specimen is the true male of $P$. sazimai and is herein described for the first time. The male described by BerTani et al. (2011) as P. sazimai is a new species, and is described herein as $P$. felipeleitei sp. nov., based on the females collected in the municipalities of Serro and Morro do Pilar, state of Minas Gerais, Brazil. Females of $P$. felipeleitei sp. nov. and $P$. sazimai are similar in size and their spermathecae have similar shape. They can be distinguished by their very distinct color pattern, with $P$. sazimai having blue metallic setae covering its body, while P. felipeleitei sp. nov. has a black color with conspicuous white rings and stripes on the dorsum of the legs and palps (Fig. 20). Furthermore, the sternum of $P$. sazimai is longer than wide (Fig. 2) and the dorsal portion of the abdomen has type III urticating setae, whereas the sternum of $P$. felipeleitei sp. nov. is as wide as long (Fig. 9) and the dorsal portion of the abdomen has only type I urticating setae.

Given that the cladistic analysis of BERTANI et al. (2011) was strongly based on male characters, the position of $P$. felipeleitei sp. nov. on that cladogram should replace $P$. sazimai, i. e., as the sister-species of $P$. vitiosum. The geographic distribution of the genus remains somewhat similar to that presented in BERTANI et al. (2011), as P. sazimai and $P$. felipeleitei sp. nov. are sympatric in some localities of Espinhaço Mountain Range in the state of Minas Gerais. However, the latter species has not yet been recorded in the state of Bahia.

The taxonomic position of $P$. sazimai is more complex. Several characters of the male palpal bulb and male tibial spur are distinct from Pterinopelma. The combination of male palpal bulb shape and keels of $P$. sazimai are similar to those found in the species of the related genus Vitalius, as the well-developed prolateral inferior and prolateral superior keels, a medially developed apical keel, a sharp retrolateral keel, a medially long embolus, a well-developed subapical keel and embolus slightly flattened and slender at its distal portion (Figs. 6-7). However, the tibial spur has two branches that are almost straight (Fig. 5) and the metatarsus of the first leg touches the tip of the retrolateral branch when folded, which is different from the condition found in the species of Vitalius, but similar to Lasiodora spp. and some species of Nhandu, for instance N. cerradensis Bertani, 2001 and N. coloratovillosus (Schmidt, 1998) (BERTANI 2001). The female spermathecae are compatible with species of Pterinopelma, Nhandu, Vitalius, and Lasiodora, but type III urticating setae on the dorsum of the abdomen occur in females of the Nhandu and Lasiodora species, but not in females of either Vitalius or Pterinopelma species. The morphology of the bulb indicates $P$. sazimai should not be included in Pterinopelma. Its inclusion in Vitalius could be justified based on the morphology of the bulb, but the tibial spur of males and the presence of type III urticating setae in females suggests that this placement may not be correct. Its inclusion in Lasidora or Nhandu are also not justified, as it lacks the stridulatory setae characteristic of Lasiodora species and the females lack the longer setae on the carapace, a synapomorphy of Nhandu. Therefore, the position of Pterinopelma sazimai is very controversial. Since the first author (RB) is conducting a cladistics analysis including all Lasiodora, Vitalius, Nhandu and Pterinopelma species, we have decided to postpone any changes in its taxonomic position.

\section{ACKNOWLEDGMENTS}

We are grateful to Alessandro Giupponi, who made us aware of the male specimen of P. sazimai in the collections of MNRJ and authorized the reproduction of the photo of the living specimen. We also thank Adriano Kury for the loan of specimens and for providing a repository for the types. Andre V. L. Freitas and Artur Furegatti (ZUEC) for specimen's loan. Support: FAPESP 2012/01093-0 and CNPq Research Fellow - Brazil for RB.

\section{LITERATURE CITED}

BERTANI R (2000) Male palpal bulbs and homologous features in Theraphosinae (Araneae, Theraphosidae). The Journal of Arachnology 28: 29-42. doi: 10.1636/0161-8202(2000)028[0029:MPBAHF]2.0.CO;2 
Bertani R (2001) Revision, cladistic analysis, and zoogeography of Vitalius, Nhandu, and Proshapalopus; with notes on other theraphosine genera (Araneae, Theraphosidae). Arquivos de Zoologia 36: 265-356. doi: 10.11606/issn.2176-7793. v36i3p265-356

Bertani R, Guadanucci JPL (2013) Morphology, evolution and usage of urticating setae by tarantulas (Araneae: Theraphosidae). Zoologia 30(4): 403-418. doi: 10.1590/S198446702013000400006

Bertani R, Nagahama RH, Fukushima CS (2011) Revalidation of Pterinopelma Pocock 1901 with descrition of a new species and the female of Pterinopelma vitiosum (Keyserling 1891) (Araneae: Theraphosidae: Theraphosinae). Zootaxa 2814: 1-18. doi: 10.11646/zootaxa.2814.1.1

Bonnet P (1958) Bibliographia araneorum. Toulouse 2(4): 30274230.

Cooke JAL, Roth VD, Miller FH (1972) The urticating hairs of theraphosid spiders. American Museum Novitates 2498: 1-43. Available online at: http://digitallibrary.amnh.org/bitstream/handle/2246/2705//v2/dspace/ingest/pdfSource/nov/ N2498.pdf?sequence=1\&isAllowed=y [Accessed: 22/09/2015]

Gerschman de Pikelin BS, Schiapelli RD (1978) Estudio de los ejemplares tipos de Lasiodora weijenberghi Thorell, 1894 y Eurypelma minax Thorell, 1894 (Araneae, Theraphosidae). Revista de la Sociedad Entomológica Argentina 37(1-4): 85-87.

Mello-Leitão CF (1923) Theraphosoideas do Brasil. Revista do Museu Paulista 13: 1-438.

Mello-Leitão CF (1943). Catálogo das aranhas do Rio Grande do Sul. Arquivos do Museu Nacional 37: 147-245.

Petrunkevitch A (1925) Arachnida from Panama. Transactions of Connecticut Academy of Arts and Sciences 27: 51-248.

Petrunkevitch A (1928) Systema Aranearum. Transactions of the Connecticut Academy of Arts and Science 29: 1-270.
Petrunkevitch A (1939a) Catalogue of American spiders. Part one. Transactions of the Connecticut Academy of Arts and Science 33: 133-338.

Petrunkevitch A (1939b) The Status of the Genus Eurypelma (Order Araneae, Family Theraphosidae). Annals and Magazine of Natural History 11(4): 561-568.

Pocock RI (1901) Some new and old genera of South American Avicularidae. Annals and Magazine of Natural History 8(7): 540-555.

Raven RJ (2005) A new tarantula species from northern Australia (Araneae, Theraphosidae). Zootaxa 1004: 15-28. doi: 10.11646/zootaxa.1004.1.2

VAlerio CE (1980) Arañas terafósidas de Costa Rica (Araneae: Theraphosidae). III. Sphaerobothria, Aphonopelma, Pterinopelma, Citharacanthus, Crypsidromus y Stichoplastus. Revista de Biologia Tropical 28: 271-296.

World Spider Catalog (2015) World Spider Catalog. Natural History Museum Bern, version 16.5, available online at: http://wsc.nmbe.ch [Accessed:14/10/2015]

Submitted: 18 November 2015

Received in revised form: 20 January 2016

Accepted: 7 February 2016

Editorial responsibility: Ricardo Pinto da Rocha

Author Contributions: RB identified the specimens, made descriptions, took photos; FL collected the specimens, took photos. RB and FL wrote the manuscript.

Competing Interests: The authors have declared that no competing interests exist. 